\title{
Case Report on a Rare Adverse Drug Reaction of Cefotaxime Induced Subacute Cutaneous Lupus Erythematosus
}

\author{
Kabakama 'C Clement ${ }^{1}$, Nandhi Nalini ${ }^{2, *}$ \\ 'Department of Pharmacy Practice, JSS College of Pharmacy, Ootacamund, The Nilgiris, Tamil Nadu INDIA. \\ ${ }^{2}$ Pediatrician and Assisstant Surgeon, Government District Headquarters Hospital Ootacamund, The Nilgiris, Tamil Nadu-643001, INDIA.
}

\begin{abstract}
Drug Induced lupus erythematosus is a variant of lupus erythematosus that resolves within days to months after withdrawal of the culprit drug in a patient. DILE can sometimes arise months to years after the exposure to drugs prescribed to treat various medical conditions. The mostly common drugs that cause DILE are Hydralazine, Procainamide, Quinidine, Isoniazid, Diltiazem, although there are few research literature studies reported of Cefotaxime induced Subacute lupus erythematosus (SCLE) in Pediatrics. A 9-year-old girl was admitted to Pediatric ward, she had past medication history of cefotaxime, After cefotaxime administration on the $4^{\text {th }}$ day of hospitalization she developed papulosquamous, erythematosus skin patch, skin rash, photosensitive annular plaques and non-scarring erythematosus lesions were seen on arms, legs and abdomen part of her body. Prognosis was better after discontinuation of cefotaxime therapy. This case report
\end{abstract}

discuss cefotaxime induced sub-acute lupus erythematosus (SCLE) with an outline of diagnosis /management and emphasis of Cascade Genetic Screening for Genotyping of Haplotypes Human leukocyte antigen (HLA). Key words: DISCLE, Cefotaxime, Adverse drug Reaction, HLA, Lympadenopathy.

Correspondence

Dr. Nandhi Nalini, Pediatrician and Assisstant Surgeon, Government District Headquarters Hospital Ootacamund, The Nilgiris, Tamilnadu -643001, INDIA.

Phone: +919443814536

Email: nalininandhi@gmail.com

DOI: 10.5530/jyp.2019.11.23

\section{INTRODUCTION}

Drug- induced lupus erythematosus (DILE) is a variant of cutaneous lupus erythematosus that resolves within days to month after withdrawal of the culprit drug in a patient and there is no underlying immune system dysfunction. ${ }^{1}$ Drug-induced subacute cutaneous lupus erythematosus (DISCLE) present with manifestation of temporally skin lesions involvement associated to drug exposure and resolving after drug discontinuation. ${ }^{2}$ Cefotaxime-induced Subacute cutaneous lupus erythematosus (SCLE) have been rarely reported with its administration in pediatric population, Management of (DISCLE) can be especially challenging in patients taking multiple mediations which are capable of triggering subacute cutaneous lupus erythematosus, Thus DILE can be easily missed..$^{3-4}$

Majority of the patients with DILE have one or more clinical symptoms of Systemic lupus erythematosus (SLE) such as arthralgia, lymphadenopathy, rash, fever and have no prior history of any autoimmune disease, Inspite of that DILE differs clinically from Systemic lupus erythematosus and that is DILE tends to have less end organ damage than SLE involvement of Renal function, Liver function and Central nervous systems are less uncommon. ${ }^{1}$ Up to $30 \%$ of the DISCLE are secondary to drugs, DISCLE always affects the skin and to be Photosensitive and located on the upper part of the body including lateral face, neck, trunk, especially to the sun exposed areas, ${ }^{4}$ The Clinical presentation of the drug induced SCLE are appearance of papulosquamous skin lesions, erythematosus skin patch, skin rash, photosensitive annular plaques and non -scaring erythematosus lesion.

Cefotaxime is a Third Generation Cephalosporin's which acts by the inhibition of the final transpeptidation step of the peptidoglycan synthesis resulting in a cell wall death of bacteria despite of its good safety profile widely used for its broad spectrum antimicrobial activity and it is on the World Health Organization (WHO) list of essential medicines.

DILE is estimated to affects 15,000 to 20,000 individual cases each year, In India the prevalence estimated at 161,000 which account incidence of DISCLE. ${ }^{5-6}$

\section{CASE DESCRIPTION}

A 9-year-old female child was admitted to pediatric ward at Government Hospital on $1^{\text {st }}$ November 2017, with complaints of abdominal pain, Heartburn, lack of appetite, loss of weight and appearance of erythematosus skin patch, her mother revealed past medication History of Cefotaxime injection administration at a dose of 1500mg for seven Days and past medical History of Gastro esophageal reflux disease (GERD), abdominal pain and recurrent chronic cough. On clinical examination child vital signs were unremarkable and she weighed $26 \mathrm{~kg}$. The laboratory investigations findings which were found abnormal were Renal Functions Test, Liver Functions and Serological Test. (Table 1)

According to the signs and symptoms of the child was diagnosed with Mesenteric lymphadenopathy $\left(\mathrm{ICD}_{10}\right.$ Code No.188.0) where by an abdominal ultrasonagraphy was done to confirm the diagnosis and abdominal pain for evaluation on the $1^{\text {st }}$ day she was administered with injection cefotaxime I.V $750 \mathrm{mg}$ q12 $\mathrm{Hr}(50 \mathrm{mg} / \mathrm{kg} /$ day),Metronidazole $500 \mathrm{mg}$ I.V q12Hr (30mg/kg/day), Tablet Diclofenac P.O 50mg twice daily, Tablet Dicyclomine P.O $10 \mathrm{mg}$ twice daily on the $2^{\text {nd }}$ day she continued with the same medications, on the $3^{\text {rd }}$ day prescribed with the same medications as well syrup antacid was added into her prescription, Interestingly on the $4^{\text {th }}$ day rapidly gradually she developed more appearance of papulosquamous erythematosus skin lesion on to the neck, forearms and the lower extremities, she showed no signs of fever, no presence of

This is an open access article distributed under the terms of the Creative Commons Attribution-NonCommercial-ShareAlike 4.0 License, which allows others to remix, tweak, and build upon the work non-commercially, as long as the author is credited and the new creations are licensed under the identical terms. 
Table 1: Clinical laboratory Test.

\begin{tabular}{|c|c|c|}
\hline Test Parameter & Observed Value & Reference Range \\
\hline Hemoglobin & $12.8 \mathrm{~g} / \mathrm{dL}$ & $12-16 \mathrm{~g} / \mathrm{dL}$ \\
\hline White blood cells & $8.2 \times 10^{3} \mathrm{cells} / \mathrm{mm}^{3}$ & $3.2-9.8 \times 10^{3} \mathrm{cells} / \mathrm{mm}^{3}$ \\
\hline Hematocrit & $38.6 \%$ & $33-43 \%$ \\
\hline Mean cell volume & $77.2 \mathrm{fL}$ & 76-100fL \\
\hline Mean cell hemoglobin & $25.6 \mathrm{pg} / \mathrm{cell}$ & $27-33 \mathrm{pg} / \mathrm{cell}$ \\
\hline Mean cell hemoglobin concentration & $33.2 \mathrm{~g} / \mathrm{dL}$ & $33-37 \mathrm{~g} / \mathrm{dL}$ \\
\hline Fasting Blood sugar & $78 \mathrm{mg} / \mathrm{dL}$ & $<100 \mathrm{mg} / \mathrm{dL}$ \\
\hline Blood urea & $42 \mathrm{mg} / \mathrm{dL}$ & $20-40 \mathrm{mg} / \mathrm{dL}$ \\
\hline Serum creatinine & $0.9 \mathrm{mg} / \mathrm{dL}$ & $0.6-1.2 \mathrm{mg} / \mathrm{dL}$ \\
\hline Blood urea nitrogen & $10 \mathrm{mg} / \mathrm{dL}$ & $8-18 \mathrm{mg} / \mathrm{dL}$ \\
\hline Aspartate aminotransferase & $46 \mathrm{U} / \mathrm{L}$ & $0-35 \mathrm{U} / \mathrm{L}$ \\
\hline Alanine aminotransferase & $34 \mathrm{U} / \mathrm{L}$ & $0-35 \mathrm{U} / \mathrm{L}$ \\
\hline Alkaline phosphates & $207 \mathrm{U} / \mathrm{L}$ & $30-120 \mathrm{U} / \mathrm{L}$ \\
\hline Bilirubin Total & $0.5 \mathrm{mg} / \mathrm{dL}$ & $0.1-1 \mathrm{mg} / \mathrm{dL}$ \\
\hline Bilirubin Direct & $0.3 \mathrm{mg} / \mathrm{dL}$ & $0-0.2 \mathrm{mg} / \mathrm{dL}$ \\
\hline Bilirubin Indirect & $0.2 \mathrm{mg} / \mathrm{dL}$ & $0.1-0.8 \mathrm{mg} / \mathrm{dL}$ \\
\hline Urine sugar & Nil & Nil \\
\hline Urine albumin & Nil & Nil \\
\hline Ketone bodies & Nil & Nil \\
\hline Anti-Ro/SSA autoantibody & $89 \%$ & $>80 \%^{(+)}$ \\
\hline Anti-La/SSB & Absent & $>45 \%^{(+)}$ \\
\hline Anti-dsDNA & $12.0 \mathrm{IU} / \mathrm{ml}$ & $>10.0 \mathrm{IU} / \mathrm{ml}^{(+)}$ \\
\hline
\end{tabular}

Hemoglobin (Hb); Hematocrit (Hct); Mean cell volume (MCV); Mean cell hemoglobin (MCH); Mean cell hemoglobin concentration (MCHC); Blood urea(BU); Blood urea nitrogen (BUN); Serum creatinine (Sr.cr); Aspartate aminotransferase (SGOT); Alanine aminotransferase (SGPT); Alkaline phosphates (ALP); Anti-Sjogren's syndrome antigen A (Anti-Ro/SSA); Anti-double stranded DNA (AntidsDNA); Anti-Sjogren's syndrome antigen B (Anti-La/SSB).

the insect bites and itching was absent, Histopathological Findings revealed mild diffuse degeneration layers of keratinocyte and serological findings showed the presence of anti-Ro/SSA autoantibodies and double stranded DNA (dsDNA) to be Positive.

The results findings from Histopathological and serological showed the presence of Ro/SS-A antibodies and her past medication history correlation and a Differential diagnosis was made of DISCLE. Cefotaxime was highly suspected and was discontinued prognosis of the child erythematosus skin lesions gradually improved from a base line after withdrawal of the offending drug. On the $9^{\text {th }}$ day child was discharged on request with following medications Capsule Omeprazole P.O 10mg once daily, syrup antacid P.O $5 \mathrm{ml}$ twice daily, syrup Cyproheptadine P.O $7.5 \mathrm{ml}$ once daily for seven days, no any other antibiotics were prescribed to the child on advice with an intervention from a Clinical pharmacist recommendation to meet with Gastroenterologist for further endoscopic procedure to rule out the likely possible of her Mesenteric lymphadenopathy.

\section{DISCUSSION}

Severe skin reactions from Cephalosporin's are very rarely but have been previously documented or occurring during co-administration with the other medications. ${ }^{7}$ Cefotaxime administration is associated with the possible adverse drug reaction such as hypersensitivity reactions, pruritis, thrombocytopenia and elevated hepatic transaminases In mostly cases DISCLE is reversible without treatment once the triggering Drugs is recognized and withdrawn although beside withdrawal of the drug for early relief Topical steroids or Topical Tacrolimus have been used for DISCLE according to the severity of the patients, The induction of the photosensitive is the common feature of the drugs which trigger DISCLE, This photosensitivity state reactions may induce SCLE skin lesions. $^{8}$

These reactions are normally classified as idiosyncratic reactions that are not related directly to drug concentration but instead may be due to an usual phenotype, Genetic susceptibility is an important feature of the serious adverse drug reactions and there is considerably interest in the possibility that development of the Genetic test to identify all those patients that are risk of the adverse event prior to prescription mighty lead to the valuable drugs being retained. ${ }^{9}$ The majority of the Drugs identified to cause Drug-induced subacute lupus erythematosus (DISCLE) and skin involvement, Hypersensitivity reactions, Suggest a possible associations with Human leukocyte antigen (HLA), The initial appearance of the Subacute cutaneous lupus erythematosus (SCLE) skin lesions in conjunction with anti Ro/SSA-autoantibody occurring as an Adverse reactions to drug induced SCLE was first reported in $1985 .^{3}$

Anti-Nuclear Antibodies(ANAs) and Ro/SSA -autoantibodies are common findings in drug induced SCLE a positive Anti- Ro result is indicated by the speckled appearance under immunofluorescence with 
ultraviolet light, ${ }^{10}$ However the presence of the anti Ro/SSA plus anti $\mathrm{La} / \mathrm{SSB}$ is associated with factors as

- Age older than $>50$ years.

- HLA-DR3.

- Absence of Anti-ds DNA antibodies.

And the presence of Anti-Ro/SSA without anti La/SSB is associated with factors as

- $\quad$ Age younger than $<22$ years.

- HLA-DR2.

- $\quad$ Presence of antids DNA antibodies. ${ }^{11}$

It has been postulated that anti Ro/SSA-autoantibody have immunogenetic stronger associations with HLA-DR2 and HLA-DR $3,{ }^{12}$ Inspite of the fact that Intrinsic genetic susceptibility may explain why some patients experiences DILE as a reaction to Drug Therapies where others do not. ${ }^{13}$

\section{HLA-Haplotypes postulation association to Drug -induced SCLE}

The human Major histocompatibility complex (MHC), comprises the genes for Human leukocyte antigen (HLA) these cell surface proteins are responsible for regulations of the immune system in humans. The HLA class I complex consist of three genes HLA-A, HLA-B, HLA-C, despite that HLA class II complex consist of the HLA-DR, HLA-DP and HLADQ genes. ${ }^{14}$

HLA molecules encoded by the HLA-genes play a crucial role in immune system, HLA- allele is not just a genetic marker but also plays an important role in the pathogenesis of the adverse drug reactions, HLA-allele presently either endogenous or exogenous antigens, thus HLA-allele is required for the activation of the drug specific T-cell receptor of the effector T-cell through recognition of the drug peptide complex bound by specific HLA-allele molecule on the antigen presenting cell, Resulting in the release of the immune mediators and adaptive immune reactions caused by the offending drug. For example, Patients with the HLA$\mathrm{B}^{\star}$ 15:02 allele is at risk for developing SJS and TEN from Carbamazepine in Southeast Asian population, ${ }^{15}$ in addition to that HLA-B ${ }^{\star} 57: 01$ is also associated with Abacavir induced Hypersensitivity reactions. ${ }^{16}$ Hence forth HLA- typing should be done before cefotaxime administration and should be an innovative approach to predict drug safety and effectiveness as to prevent unwanted drug related problems.

DISCLE is more common in adult especially elderly patient of above 50years of age and the ratio female to male is $3: 1,{ }^{17}$ Cefotaxime induced SCLE in pediatric is rare entity, However a few recently literature have been reported of cephalosporin's to cause Drug induced subacute lupus erythematosus and have seen with cefipime. ${ }^{13}$ This Case emphasis the importance of recognizing severe drug related adverse events and avoidance of unnecessary prescribing of antibiotics in pediatric population. Treatment and Management of the Drug induced SCLE focuses on eliminating the underlying cause controlling symptoms and minimizing complications, identification of the possible candidate drug, discontinuation of the causative drug and sun protection are the best way to treat patients who have the drug induced sub -acute cutaneous lupus erythematosus. ${ }^{18}$

The Mostly common drugs that cause DILE are Hydralazine, Procainamide, Quinidine, Isoniazid, Diltiazem, Minocydine, Terbinafine, ${ }^{19}$ Esomeprazole, ${ }^{20}$ omeprazole, Doxcycline, ${ }^{21}$ Leflunomide, ${ }^{8}$ Cefipime,${ }^{13}$ Doxorubicin $^{22}$ Rituximab ${ }^{23}$ Genetic predisposition play a role Hydralazine induced DILE has been observed with the increase frequency in association with Human leukocyte antigen (HLA-DR4). ${ }^{13}$ In this Case event of cefotaxime induced SCLE in our patient according to severity assessment scale by Modified Hartwig and Siegel Severity Scale(MHSSC) showed that Adverse drug reaction (ADR) is moderate level 3 which requires the suspected drug to be withheld or discontinued, ${ }^{24}$ Cefotaxime administration showed a Definite association for the adverse drug reaction.

\section{CONCLUSION}

DISCLE occurrences in pediatric population is quite unusual, the standard treatment for drug -induces SCLE, to this patient is mainly discontinuation of the responsible drug. However, Physicians should review past medication history through out before prescribing and identification of the susceptible individuals for drug-induced SCLE may be facilitated in the future by the use of the biomarkers and the ability to predict adverse effect based on the principle of clinical pharmacogenomics. Nevertheless, HLA genotyping should be a future routine in clinics prior to Drug Therapy in order to prevent the potential Serious Adverse events (SAEs) and Adverse drug reactions (ADRs) due to Drugs induced SCLE.

\section{ACKNOWLEDGEMENT}

Authors greatly appreciate the assistance and Support given by the Health Care Staff of Government Headquarters Hospital.

\section{CONFLICT OF INTEREST}

The authors declare no conflict of interest.

\section{ABBREVIATIONS}

TEN: Toxic Epidermal Necrolysis; SJS: Stevens-Johnson syndrome; DISCLE: Drug-induced subacute cutaneous lupus erythematosus; DILE: Drug induced lupus erythematosus; SCLE: Subacute cutaneous lupus erythematosus; SLE: Systemic Lupus erythematosus; IV: Intravenous; P.O: By Mouth; $\mathrm{ICD}_{10}$ : International classification of disease, Tenth Edition.

\section{REFERENCES}

1. Fritzler MJ. Drugs recently associated with lupus syndrome. Lupus. $1994 ; 3(6): 455-4$

2. Antonov D, Kazandjieva J, Etugov D, Gospodinov D, Tsankov N. Drug-induced lupus erythematosus. Clin Dermatol. 2004;22(2):157-66

3. Lowe G, Henderson CL, Grau RH, Hansen CB, Sontheimer RD. A systematic review of drug-induced subacute cutaneous lupus erythematosus. $\mathrm{Br} \mathrm{J}$ Dermatol. 2011;164(3):465-72

4. Chin, Krati. Lupus Erythematosus. Drug-Induced Satpearls. 2017.

5. Chang C, Gershwin ME. Drugs and autoimmunity a contemporary review and mechanistic approach. J Autoimmun. 2010;34(3):266-75.

6. Kumar A. Indian guidelines on the management of Systemic lupus erythromatosus. J Indian Rheumato. 2002;10:80-96.

7. Eric M, Richard C. A retrospective population analysis of adverse reactions associated with oral and parenteral use of Cephalosporins. J Allerg Clin Immunol. 2015;135(3):745-52.

8. Singh H, Sukhija G, Tanwar $V$, Arora S, Bhutani J. Rare Occurrence of Drug Induced Subacute Cutaneous Lupus Erythematosus with Leflunomide Therapy. J Clin Diagn Res. 2016;10(10):OD06-OD07.

9. Anna K. Pharmacogenomics of adverse drug reactions. Biomed central. 2013;115-7.

10. Arbuckle R, McClain T, Rubertone V, Scofield H, Dennis J, James A, et al. Development of autoantibodies before the clinical onset of systemic lupus erythematosus. N Eng J Med. 2003;349(16):1526-33.

11. Gálvez J, Sáiz E, López P, Pina MA, Carrillo A, Nieto A, et al. Diagnostic evaluation and classification criteria in Sjögren's Syndrome. Joint Bone Spine. 2008;21(6):989-1010.

12. Hernendez M, Leal G, Michael M. The meaning of anti- Ro and anti-La antibodies in primary sjogren syndrome. Autoimmune Rev.2011;10(3):123-5.

13. Catharine K, Dirk M. Drug induced lupus erythematosus. Available from: http:// www.emedicine.medscape.com/article/1065086\#

14. Horton R. Gene map of the extended human histocompatibility complex. Nat Rev Genet. 2004;5(12):889-99.

15. Chung H. A marker for Stevens-Johnson syndrome Nature. Medical Rev Genet. 2004;428(6982):486. 
16. Mallal S. Association between presence of HLA-B*5701, HLA-DR7 and HLA-DQ3 and hypersensitivity to HIV-1 reverse transcriptase inhibitor Abacavir. Lancet $J$. 2002;359(9308):727-32.

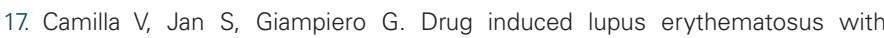
emphasis on skin manifestations and the role of anti-TNF alpha agents. JDDG. 2012;10(12):889-97.

18. Yi Chen, Yu Wu. Ticlopidine induced subacute cutaneous lupus erythematosus a Case report. Dermatol Sinica. 2014;32(3):183-6.

19. Callen J, Hughes P, Kulp C. Subacute lupus erythematosus drug induced by Terbinafine a Case report. Arch Dermatol. 2001;137(9):1196-8.

20. Alcantara J, Truchelo M, Gonzalez C, Jaen P. Esomeprazole induced subacute cutaneous lupus erythematosus. Actas Dermo. 2011;102(8):638-40.
21. Miller K, Chu J, Patel R, Kamino H. Drug induced subacute cutaneous lupus erythematosus related to Doxcycline. Dermatol J. 2011;17(10):273-5.

22. Chen $K$, Chen J, Lim P, lqbal M. Drug induced subacute lupus erythematosus with Doxorubicin. J Acad Dermatol. 2012;67(6):153-8.

23. Lis S, Brzezinska L, Widuchowska M, Kucharz E. Subacute cutaneous lupus erythematosus in the course of rheumatoid arthritis: a relationship with TNF antagonists and Rituximab therapy. Immunopharmacol Immunotoxicol. 2013;35(3):443-6.

24. Naranjo CA, Busto U, Sellers EM, Sandor P, Ruiz I, Roberts EA, et al. A method for estimating the probability of adverse drug reactions. Clin Pharmacol Ther. $1981 ; 30(2): 239-45$.

Article History: Submission Date : 13-06-2018; Revised Date : 24-07-2018; Acceptance Date : 03-10-2018.

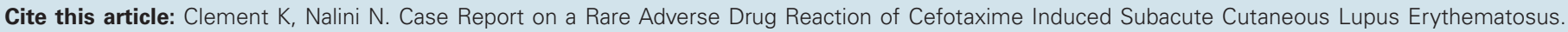
JYoung Pharm. 2019;11(1):108-111. 